\title{
Exploring the Progress of Electronic Technology and Investment Hotspots in China's New Energy Vehicles
}

\author{
Cao Zhiliang \\ Institute of Intelligent Manufacturing and Automotive, Chongqing Technology and Business \\ Institute, Chongqing Hechuan, China, 401520
}

Keywords: new energy vehicles; electronic technology; progress; investment hotspots

\begin{abstract}
In recent years, the per capita income level of Chinese residents has been continuously improved, the number of car ownership has been increasing (including new energy vehicles occupying a certain amount), automotive electronic technology has been widely used in automobiles, and the automotive electronics industry has also developed rapidly. Automotive users are increasingly demanding car comfort and safety, so it is necessary to continuously improve automotive electronics technology. This paper expounds the definition of automotive electronics industry, the classification of automotive electronic products, and analyzes the progress of China's new energy automotive electronic technology and China's new energy automotive electronics technology investment hotspots.
\end{abstract}

\section{Introduction}

As the number of cars is increasing, the demand for oil is increasing. To achieve the goal of energy saving and environmental protection, new energy vehicles have emerged. With the continuous development of technology and economy, the demand for automobiles by residents is constantly increasing, which also promotes the development of the automotive electronics industry.

\section{Automotive electronics industry overview}

\subsection{Automotive electronics industry meaning}

Automotive electronics technology is the electronic information technology and related electronic technology used in automobiles. The application of automotive electronics technology can promote the sustainable development of the automotive industry. As a result, the range of applications and applications of automotive electronic technology is also increasing, and automobiles have become mechatronic products. The application and innovation of automotive electronics technology can effectively improve the safety and comfort of automobiles. The study found that the number of single-chip microcomputers used in some luxury cars is about 50 .

\subsection{Automotive electronics classification}

Automotive electronics can be divided into the following two categories: First, automotive electronic control devices. Such devices need to cooperate with the automotive mechanical system 
to play their role, mainly including engine control systems, chassis control systems, etc.; second, invehicle electronic devices. Unlike the previous category of automotive electronics, it can be used independently in automobiles, which mainly include automotive information systems, navigation systems, and so on.

\subsubsection{Automotive engine electronic control system}

This system belongs to an important automotive electronic product, which is of great significance for improving the performance of automobile engines and reducing the fuel consumption of automobiles. It mainly includes the following:

Electronic ignition system, The system uses the microprocessor to effectively process the sensor to collect data information related to the ignition parameters, clarify the ignition time, and issue an ignition command to the ignition system.

Electronic fuel supply system,Such systems can be divided into two types: electronic feedback carburetor and electronic fuel injection system. The main function of electronic feedback carburetor is to control the optimal air-fuel ratio of different operating states of the engine; the electronic fuel injection system is controlled by microcomputer. Automobile oil and gas mixing, atomization, ignition time, etc., to achieve the goal of reducing emissions and improving engine performance.

Electronic purifier,Its main function is to analyze the exhaust gas of the automobile, so as to clarify the amount of exhaust gas circulation and effectively reduce harmful substances in the exhaust gas of the automobile.

\subsubsection{Automobile chassis electronic control system}

The main function of this electronic system is to optimize the driving, steering and braking performance of the car. At this stage, such electronic control systems mainly include: electronically controlled power steering systems, anti-lock braking systems, and the like. It mainly includes the following:

Electronically controlled power steering system,The system uses sensors to collect data such as vehicle speed, lateral acceleration, steering wheel input, etc., and uses the microprocessor to process the data, and uses an electro-hydraulic proportional valve to adjust the direction of the steering wheel to achieve the purpose of controlling the direction of travel of the vehicle.

Electronically controlled stepless automatic transmission, The use of electronic technology can achieve the goal of stepless automatic change, and such products have been widely used in luxury cars.

Electronic anti-lock braking system,The system can be divided into two types: full electronic damping system and anti-lock braking system. The full electronic damping system can automatically adjust the damping amount when the uniform deceleration braking and constant speed setting have been set, thus achieving the braking target; The brake system monitors the wheel speed and compares the wheel speed with the vehicle speed to calculate the wheel slip. This not only ensures the stability of the vehicle, but also shortens the vehicle's braking distance. This system has become a must-have for all vehicles.

Electronic suspension system,It mainly includes two kinds of semi-active and active type. The semi-active electronic suspension system uses the shock absorber to control; the active electronic suspension system can reduce the vibration in different directions.

\subsubsection{Body electronic control system}

Such technologies will have an impact on car comfort, safety, and communication functions. Among them, the field of view control technology uses electronic technology to control the car 
lighting system and the turn signal lamp, and also includes the use of electronic control technology to control the wiper, the scrubber, etc.; the convenience refers to the convenience of loading and unloading the luggage while ensuring the driver and passengers enter and exit the car. At the same time, it is necessary to use electronic technology to control electric sunroof, door locks, etc.; body electronic control equipment mainly includes lighting system, automatic seat system, multimedia system and so on.

\subsubsection{Automotive Information System}

This system can timely and accurately reflect all kinds of information involved in the driving process of the car, including: driving speed, mileage, water temperature, communication information, etc. It is mainly composed of the following systems: First, an electronic display system. At this stage, a large number of electronic technologies are used in the automotive information system to show the driver's driving situation and operating status, and to automatically detect faults; secondly, the communication system. It mainly includes car phone, car TV and other systems.

\section{Progress in electronic technology of new energy vehicles in China}

With the continuous development of the automotive industry, the sales volume of new energy vehicles continues to increase, and the requirements for new energy vehicle electronic technology are also constantly improving. Compared with Western countries, China's research on automotive electronics technology is not deep enough. Some enterprises in China actively cooperate with foreign companies to introduce and learn advanced foreign technology, so that automotive electronics technology has achieved certain development. At this stage, China has carried out indepth research and research and development on vehicle control and integration, which has promoted the development of China's new energy vehicle electronics industry.

\subsection{The development of in-vehicle information service is faster}

In recent years, China has paid more and more attention to the development of the new energy automobile industry, and has issued policies and laws related to the Internet of Vehicles, such as: "Technical Requirements for Vehicle Terminals for Road Transportation Vehicles Satellite Positioning System" and "Works on Strengthening Road Traffic Safety" Opinions, etc., and clearly stated in the "Opinions" that all heavy-duty trucks and semi-trailer tractors must be equipped with satellite positioning equipment before leaving the factory, and they must be recorded in the relevant regulatory platform and service platform. By formulating and implementing these policies, the normative and scientific management of commercial vehicles can be improved. After the government departments issued these policies, companies need to actively build a car network. At this stage, the development direction of automotive technology is intelligent and car networking (for example: SAIC and Ali cooperate). As early as April 2015, Intel Corporation cooperated with CCCC Road and Star Channel to develop a commercial vehicle networking terminal based on the Intel Quark processor. And Intel said that the data information that the terminal attaches to is between different ports, for example, the data is input into the cloud by the terminal device; the data is transmitted by the logistics enterprise to the car owner and then transmitted to the cloud. When the device collects the data information, it will save it to the cloud in time, and analyze the big data, and then transmit the analysis result to the terminal to provide the corresponding information service for the driver, which helps the driver to avoid the traffic congestion section and improve the driving efficiency. In May of the same year, Cadillac cooperated with Anjixing to develop and launch the 4G LTE service, which is of great significance to promote the development of vehicle 
networking technology. In the future, the level of intelligence of the car will continue to increase, which not only improves driving comfort, but also improves driving safety and environmental protection.

\subsection{The development technology of vehicle controllers is developing rapidly}

The main function of the new energy vehicle controller is to control the various parts and energy of the car. From the aspect of product type analysis, it can be divided into vehicle power battery control system, vehicle motor control system and so on.

At this stage, some enterprises in China have studied and introduced advanced foreign technology, and cooperated with well-known universities or research institutes to conduct in-depth research on new energy vehicle electronic technology. Now they have formed an industrial chain and applied these automotive electronic technologies to new energy vehicles. among. China's automotive controller manufacturers mainly include: FAW, SAIC, Chery and other vehicle manufacturers and Wanxiang electric vehicles and other parts manufacturers. At present, China has mastered the new vehicle controller technology for new energy vehicles, and has independently developed a large number of new energy vehicle electronic control products, and some products have begun to be produced and applied to new energy vehicles; compared to advanced countries, China for automobiles the research on electronic technology is not deep enough. Therefore, the research and development level and industrialization level of electronic controllers for new energy vehicles in China are significantly lower than those of well-known foreign companies. Therefore, China needs to introduce new energy vehicle electronic controller hardware and development tools from abroad. Some vehicle manufacturers are still using electronic controllers for new energy vehicles produced by well-known foreign companies. The application range of China's domestic new energy vehicle electronic controllers is narrow.

\subsection{Power management system has made some progress}

In the new energy vehicle electronic control system, the battery management system is an important electronic control system, its main function is to evaluate, manage and protect the power battery equipment in new energy vehicles. At this stage, most of the research on battery management systems in China comes from universities, research institutes and enterprise R\&D centers. The battery management system is relatively complete and can be used in experimental models, but China's domestic power management system is still in experimental or small-scale production. In the link, a complete industrial chain has not been formed. The survey found that China's domestic power management system is jointly developed and produced by enterprises and universities. For example, Tongji University in China cooperated with a number of battery research and development companies to develop a centralized control battery management system for new energy vehicles; Beijing University of Aeronautics and Astronautics independently developed Lithium-ion power battery balanced charging and its management system, and this technology has been widely used in enterprises such as FAW and Dongfeng Electric, and has been declared patent.

\section{China's new energy vehicle electronic technology investment hotspot}

\subsection{Power battery}

In recent years, countries around the world have paid more and more attention to the environment and energy. Oil is a non-renewable resource, and the fuel used in traditional cars is oil, which produces a lot of pollutants during the combustion process. In order to reduce the demand for 
petroleum resources in the automotive industry and reduce pollution emissions, countries around the world have begun to develop new energy vehicles. In order to promote the stable and rapid development of the new energy automobile industry, our government departments have issued a number of policies and laws and regulations. With the rapid development of the new energy automobile industry, the demand for power batteries in the market is gradually increasing. As early as 2015, China's State Council officially issued the "Made in China 2025", which clearly proposed the development strategy of the new energy automobile industry, which clearly stated that until 2020, China needs to guarantee technologies related to new energy vehicles such as power batteries and drive motors. Overtake the Western countries and occupy most of the market in China. In 2016, China established the Power Battery Innovation Center, whose main purpose is to develop new power batteries and promote the stable development of the new energy vehicle industry. In the same year, Guoxuan Hi-Tech, Geely, Tianjin Lishen and other enterprises also invested in power battery research and development and manufacturing. The development and production of power batteries is an important factor affecting the development of the new energy vehicle industry. In the future, China's power battery manufacturers need to strengthen research on power battery safety, endurance, and charging speed.

\subsection{Nuclear power devices}

In recent years, China's government departments have introduced some policies and laws and regulations to support the development of new energy auto industry. Semiconductors, sensors and other device research and development, production companies need to seize this opportunity to strengthen research and development of related devices. Under the support of market demand and national policies, some enterprises in China that develop and produce new energy vehicle core components have achieved certain results, such as: CRRC Times Electric, BYD Microelectronics, etc. At this stage, most of the new energy vehicles use power semiconductors (such as IGBTs). It is precisely because the new energy vehicle powertrain system is developing towards electrification, and the number of semiconductor components used in automobiles is gradually increasing. This is also an important opportunity for the development of related manufacturers in China.

\subsection{Charging pile}

In order to promote the stable development of the new energy automobile industry, the State Council issued the "Energy Conservation and New Energy Vehicle Industry Development Plan (2012-2020)" in 2012, which clearly pointed out that China needs to increase the number of new energy vehicle charging pile construction to meet the new Energy car charging requirements. In 2016, China began to increase the construction of charging piles (a large number of charging piles were built in highways and cities), and in 2017, China carried out two tenders for car charging piles. The construction of charging piles is also an important factor affecting the development of new energy automobile industry. It is also a key point and hot spot for investment in new energy automobile industry.

\subsection{Service operations}

Automobile manufacturing requires a lot of time, technology, and capital, and the rate of capital recovery is slow, so most investors will not choose to invest in the vehicle manufacturing industry. In order to ensure the interests of investors, in the investment process, they need to invest in service industries, battery recycling and other industries related to the new energy automobile industry, and constantly improve the new energy vehicle industry chain. These industries related to the new 
energy automobile industry are also investment. The investment focus of the company, for example, because of the low energy consumption of new energy vehicles, it can be applied to the logistics leasing industry, which can effectively save the cost of leasing enterprises.

\title{
4.5. Driverless
}

With the continuous development of human society, many countries have begun to develop driverless technology, and this technology is more in line with the development requirements of the automotive industry. At this stage, world-renowned Internet companies and automobile manufacturers are actively involved in the research and development of driverless technology. China's FAW, SAIC, BAIC, Chery, Xiaomi, Baidu and other companies have begun research and experimentation of unmanned technology. Compared with some foreign companies, China's unmanned driving technology is in the initial stage, and some technologies and research are not deep enough and perfect. China expects to apply unmanned technology to the automotive industry by 2020 and achieve industrialization goals by 2025. The industry will also face investment opportunities of 5 to 10 years.

\section{Conclusion}

In recent years, due to the continuous improvement of the income level of Chinese residents, the safety and comfort requirements of the vehicle have also been improved. In order to meet the needs of users, enterprises need to vigorously develop automotive electronic technology. It can be said that the application of automotive electronic technology will be It has a huge impact on the development of the automotive industry.

\section{Acknowledgement}

\author{
Science and Technology Extension Project of Chongqing Education Commission \\ (GZTG201614).
}

\section{References}

[1] Qing Lei. China's New Energy Vehicles have Broad Prospects for Development - Interview with Wang Qing, Assistant Director of the Market Economy Research Institute of the State Council Development Research Center [J]. China Power Enterprise Management, 2016(5): 48-50.

[2] Xu Jianwei, Li Jinfeng, Yan Huan. Current Hot Issues and Suggestions for the Development of New Energy Vehicles

[J]. Economic Research Reference, 2016(54): 5-9

[3] Xi Min. Research and Development of Measurement and Control System for New Energy Vehicle Test Bench[J]. Electronic Technology and Software Engineering, 2016(3): 75-75.

[4] Wei Jiarong. Comparative Study on the Models of Commercial Ecosystem of New Energy Vehicles[J]. China International Finance (English), 2017(19): 18-19.

[5] Cao Yingfan. Analysis of Investment Value of New Energy Automobile Company_-Taking BYD as an Example[J]. China Business Review, 2017(5):168-169

[6] Cheng Hanping. Analysis of Control Technology for New Energy Vehicles and Motor Drives[J]. Times Auto, 2017(22): 45-46. 